\title{
Beta-D-Glucopyranose Monohydrate
}

National Cancer Institute

\section{Source}

National Cancer Institute. Beta-D-Glucopyranose Monohydrate. NCI Thesaurus. Code C61651.

The monohydrate form of the beta isoform of D-glucopyranose, a synthetic simple monosaccharide as an energy source. D-glucopyranose is oxidized in various tissues either under aerobic or anaerobic conditions through glycolysis, and the oxidation reaction produces carbon dioxide, water and ATP. 